\title{
Location changes of "Wydrzany" groundwater intake in polish part of the Uznam Island aimed at groundwater state improvement
}

\author{
Ryszard Hoc ${ }^{1}$, Andrzej Sadurski ${ }^{2}$, Zenon Wiśniowski ${ }^{1}$, \\ ${ }^{1}$ Pomeranian Branch of Polish Geological Institut NRI, Szczecin; \\ ${ }^{2}$ Marine Branch of Polish Geological Institut NRI, Gdańsk, and Nicholas Copernicus \\ University, Tor, Poland
}

\begin{abstract}
The water supply of the eastern part of the Uznam Island comes from two groundwater intakes: Zachód and Wydrzany. The threat to the resources part of the groundwater intake Wydrzany approach results from the progressive concentration of chloride ion, mainly in the southern part of the intake and locally in the central part of the water intake. After the launch of the intake at the end of the 1970s, the development of the water table depression, currently reaching the shore of the Lagoon, caused the frontal infiltration of the brackish waters of the Szczecin Lagoon into aquifers and a small amount of brine ascesion from the mesozoic strata. To determine the genesis of salinity, isotopic tests were carried out, including ${ }^{37} \mathrm{Cl}$ chlorine isotopes. Water for the Szczecin Lagoon and groundwater, including the aquifer of the Cretceous, have been sampled.
\end{abstract}

\section{GEOLOGICAL AND HYDROGEOLOGICAL OUTLINE}

The studied area of research is located in the western part of the Polish Baltic coast, in the the town of Świnoujście, West Pomeranian Voivodeship (fig. 1). There are two morphological forms in the landscape of this island. These are contrasting flat delta areas, being part of the so-called "Swina's Gates" and a varied ordinate of the upland of this island. The above mentioned forms of landscape differ from one to another not only in the genesis of the uprising, but also in different age. The decline is in Young Holocene, while the the upland area was shaped eventually during the deglaciation at the end of Pleistocene in this area. The "Świna Gate" it is the area between the Uznam and Wolin moraine uplands, which is a coastal lowland with an altitude in range of $0.3 \div 20.0 \mathrm{~m}$ above sea level, closing the passage between the Szczecin Lagoon and the Pomeranian Bay.

The outer waters for the island of Usedom are: poorly saline, with salinity lower than the open sea, due to the freshening influence of Odra River waters. The share of the "Wydrzany" intake in exploitation resources of groundwater in the Polish part of the Usedom island is Q $=300 \mathrm{~m}^{3} / \mathrm{h}$. To determine the cause of salinity and solve the problem associated with operational resources of the intake, cartographic, geophysical and laboratory analyses (chemical and isotopic) were made. The results of these works have been applied in the developed mathematical flow model of the considered area.

The multiaquifer formation in the eastern part of the Uznam Island, characterized in detail by numerous hydrogeological works (Matkowska, 1997) occurs in Quaternary sediments up to a depth of 30-50 m, depending on the shape of the Pre-Quaternary sediments. The intrusion of salt water into the Quaternary aquifer prevents natural inflow of rainwater. 


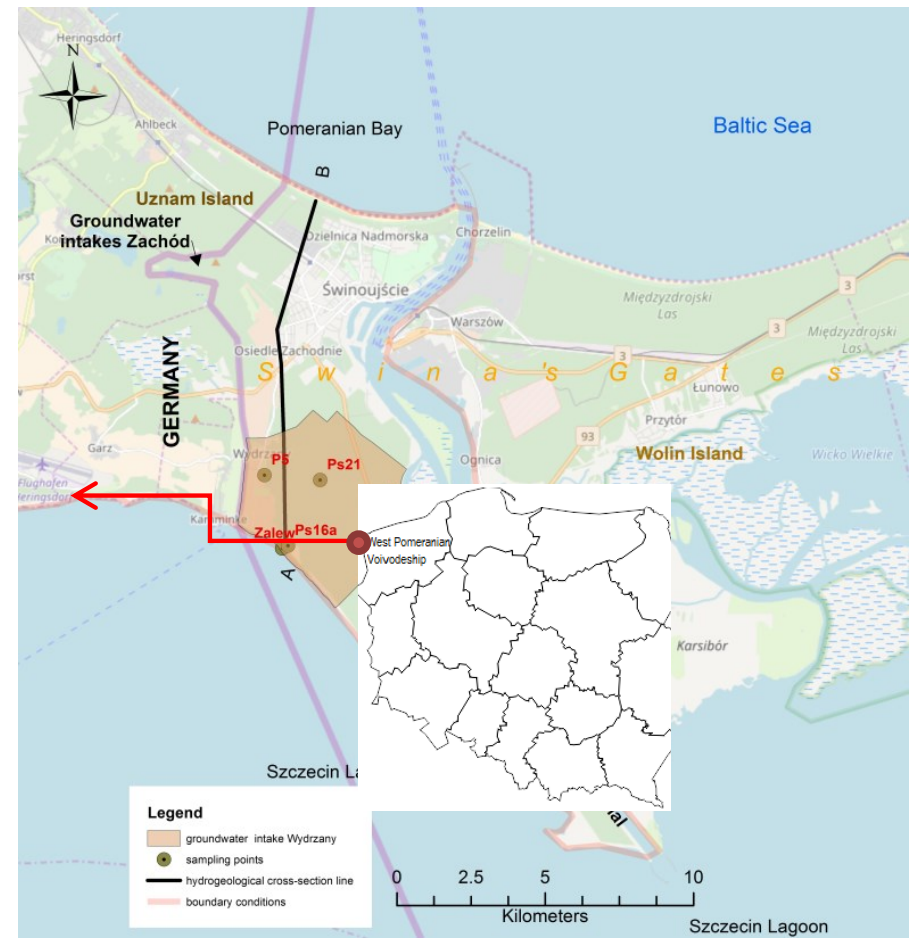

Figure 1. Location of the research area and groundwater intake "Wydrzany".

\section{Hydrogeological conditions and flow systems of groundwater}

The hydraulic head is higher in this aquifer than in the Cretaceous one. The infiltration conditions are generally very favorable. The $80 \%$ of the Uznam Island surface area is covered by permeable sediments. In the discussed area, there are also numerous cavities without outflow and inter-dune depressions which facilitate additionally infiltration. The thickness of the aeration zone depends mainly on the relief of the terrain surface and on the dune areas, it occurs at a depth of one to five $m$ beyond the cone depression of the intake. Groundwater drainage takes place through the wells of the intakes and partial outflow to the surface waters. A small amount, these waters are drained by drainage ditches and pumping stations.

In the Cretaceous aquifer, there are mineralized waters and brines at depth, found in the sandy sediments of the lower Cretaceous at a depth of about $200 \mathrm{~m}$. The groundwater circulation system in the discussed area can be reduced to the following scheme:

- under natural conditions, underground waters within the island are supplied only by infiltration of atmospheric precipitation,

- in the conditions of intensive exploitation of intakes, the lateral inflow of waters from the coastal and lake reservoirs is intensified.

Based on the analysis of the collected materials, three layers of the model were identified: Ist layer - groundwater level; IInd layer - weakly permeable sediments - muds and clays; IIIrd layer - the Quaternary aquifer, developed and fluvioglacial sands and gravels. The layer I and III remain in the hydraulic bond. 


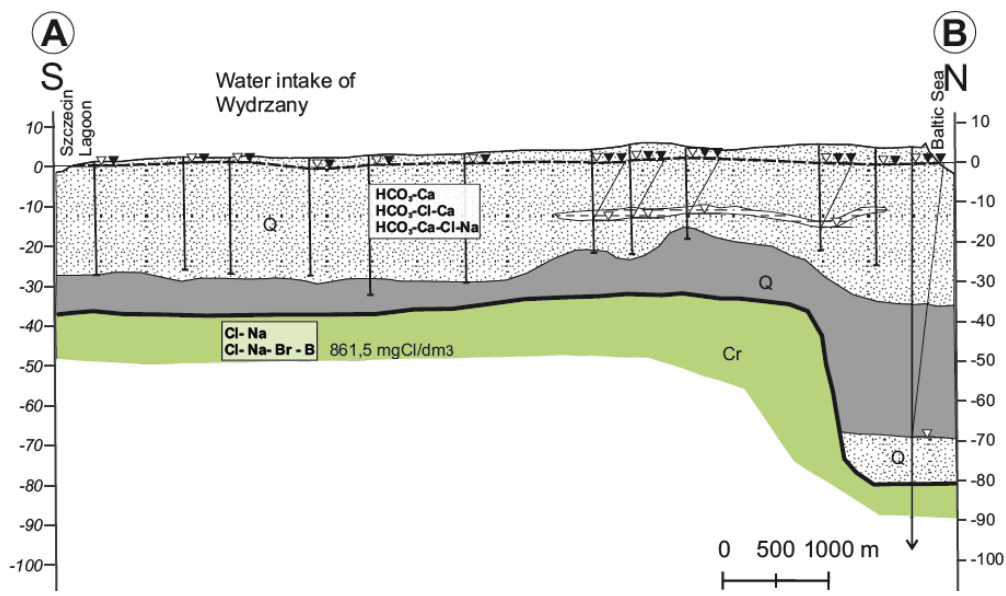

Figure 2. Hydrogeological cross-section through island of Uznam Island.

\section{INTRUSION AND ASCENSION OF BRACKISH AND SALT WATER}

During cartographic and geophysical works, the range and depth of occurrence of salt water in aquifer was determined. The occurrence of salinity in the first aquifer, which may be caused by infiltration of saline water from drainage ditches, has been found. The concentration of chloride ion in the years 2007 - 2015 on the "Wydrzany" intake varied from $15.0 \mathrm{mg} / 1$ to $447.0 \mathrm{mg} / 1$ and had an increasing trend.

\section{METHOD AND SCOPE OF INVESTIGATION}

The purpose of the research was to determine the genesis of the increase of chloride concentration in groundwater. Then, on the basis of the results, a solution was proposed in order to preserve the size of operational resources of the intake or even increase them, as well as to improve the status of groundwater in the Polish part of Uznam island. To solve the problem, geophysical and laboratory works were carried out, based on which a mathematical model of groundwater flow in the discussed area was developed. In order to explain the genesis of the salinity of the first aquifer in the southern part of the Uznam Island, it was made: geoelectrical logging, chemical analysis to determine the $\mathrm{Cl}^{-}$ion for surface and groundwater samples, isotopic analysis of groundwater and surface water samples: $\delta^{34} \mathrm{~S}$ $\left(\mathrm{SO}_{4}{ }^{2-}\right), \delta^{13} \mathrm{C}$ (dissolved inorganic carbon), $\delta^{37} \mathrm{Cl}, \delta^{18} \mathrm{O}\left(\mathrm{H}_{2} \mathrm{O}\right), \delta^{2} \mathrm{H}\left(\mathrm{H}_{2} \mathrm{O}\right)$.

The model of chloride ion transport in the MT3D program (MT3DMS version) has been developed for this task, which allows the calculation of mass transport in the advectiondispersion stream under steady state or transient flow conditions. Model calculations assume that chloride ions are transferred in the groundwater stream, like conservative tracer. The calculations did not take into account the dissolution and precipitation of mineral phases. The $\mathrm{Cl}^{-}$ion ionization of the $\mathrm{Cl}^{-}$ion was input by boundary conditions.

The basis for determination of external boundary conditions were the average concentrations of chloride ions observed in the waters of Szczecin Lagoon $(800 \mathrm{mg} / \mathrm{l})$, Świna R. (1000 $\mathrm{mg} / \mathrm{l})$ and Baltic Sea $(2000 \mathrm{mg} / \mathrm{l})$. The internal boundary conditions were applied to reflect the concentrations of chloride ions in the groundwater streams in the area of the "Wydrzany" intake. In the absence of data on the distribution of chloride ions in the vertical profiles of the aquifer, a constant initial value of concentrations in the entire profile of the aquifer was assumed. 


\section{RESULTS}

The obtained results of isotopic research allow to see, on the one hand, the separateness of the P5 in relation to the other tested points, and on the other, the similarities between the composition of waters originating from the Szczecin Lagoon (indirectly the Baltic Sea) and groundwater included in the Ps 16a piezometer. The waters included in the piezometers Ps21 and Ps3a also show isotopic-hydrogeochemical similarity with the waters of the Szczecin Lagoon, however, the share of this "constituent" becomes smaller as the distance from the source of salinity increases.

As it results from the model calculations regarding water flow and chloride ions migration, in the conditions after the moved of the groundwater intake Wydrzany, saline water will not be supplied to it, or it will be irrelevant to water quality. In the figure below it can be seen that already in the initial conditions $(\mathrm{t}=0$ years $)$ in the area of water runoff for chloride ion concentration, it is from 21 to $84 \mathrm{mg} / \mathrm{l}$. After transferring the intake to the north, in the area with saline waters, chloride ion concentrations will decrease, and after 15 years in the "saline" area, the average Cl-ion concentrations fall below $250 \mathrm{mg} / \mathrm{l}$. Changes in chloride ion concentrations in the area of the southern part of the island of Uznam Island, with the proposed exploitation of water on the "Wydrzany" intake, are presented in the figure below.
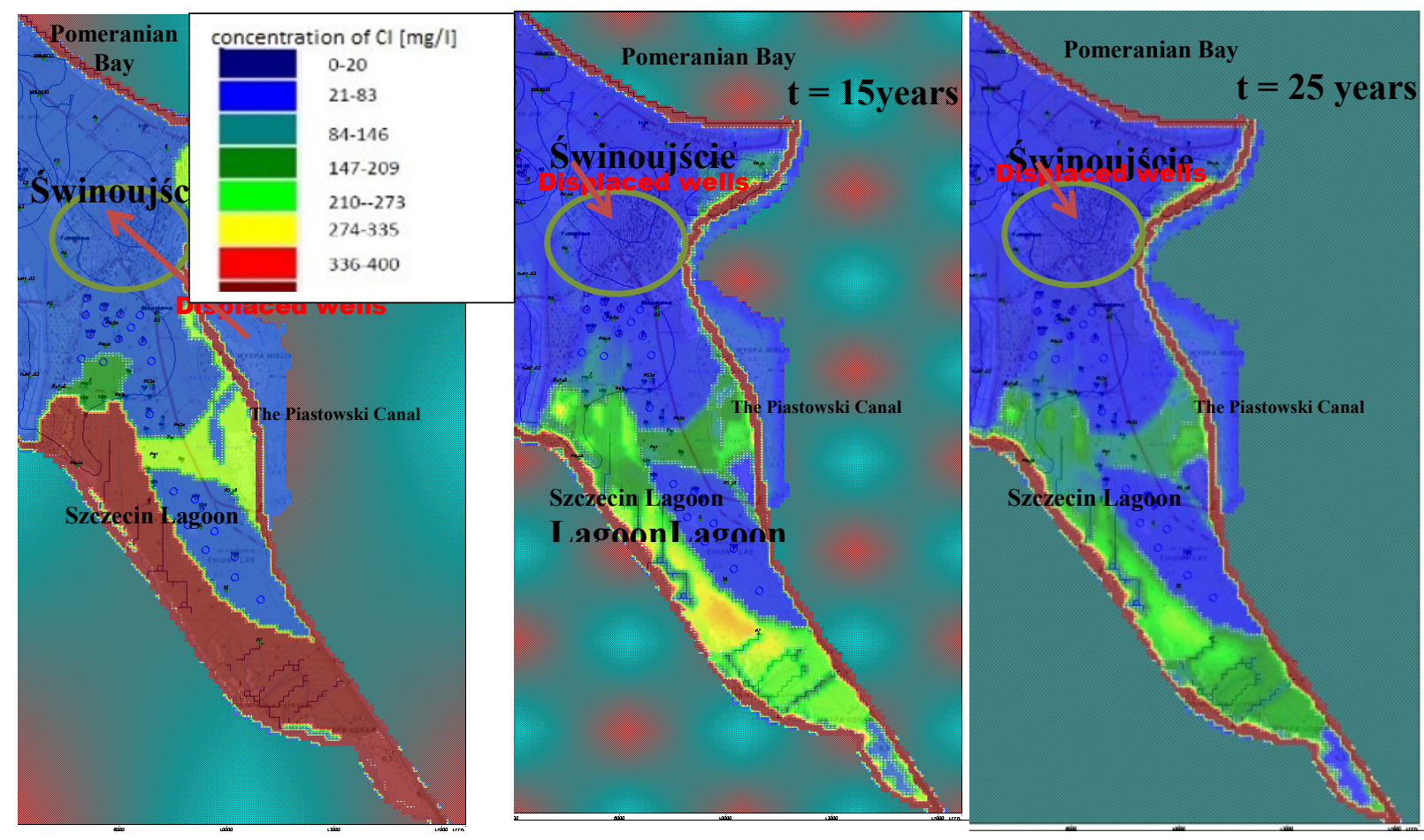

Figure 3. Changes in the salinity of main aquifer of usable level after dislocating water intake "Wydrzany", located on the Uznam Island.

\section{PROPOSED SOLUTION FOR IMPROVING THE WATER CONDITION AND OPERATING RESOURCES}

Based on analysis of water circulation conditions of water in the first and the second aquifer and also groundwater connection with surface waters, it was considered necessary to shift the resource area of the "Wydrzany" intake to the present area. In order to verify the validity of the proposed changes, a water balance was made for this intake in the first and second 
aquifer. However, on the basis of simulations in the mathematical model, changes in the concentration of chloride ion in waters captured on this approach are depicted.

On the basis of model, field and laboratory works, it was confirmed that the lack of actions aimed at moving the groundwater intake Wydrzany to the north will cause a deepening of the salinity of the intake water. The positive scenario consisting in lowering the chloride concentration in the captured groundwater at the "Wydrzany" intake is related to the displacement of groundwater intake. This solution will allow maintaining disposable resources at the current level, and the salinity of water may decrease to approximately 30 $\mathrm{mgCl} / \mathrm{l}$. The confirmation of this conclusion is the result of modelling of chloride transport, which shows that in waters of the main aquifer there are concentrations in the range of 21 $83 \mathrm{mg} \mathrm{Cl} / 1$ in the range of impact of the "Wydrzany" intake. At the same time, in areas where groundwater salinity is currently observed, a steady decline in chloride ion concentrations is observed. The analysis shows that the proposed change, mainly in the area of the location of the resource area of the "Wydrzany" intake, will meet the basic environmental objective of improving the quality and quantity of groundwater on the Uznam Island.

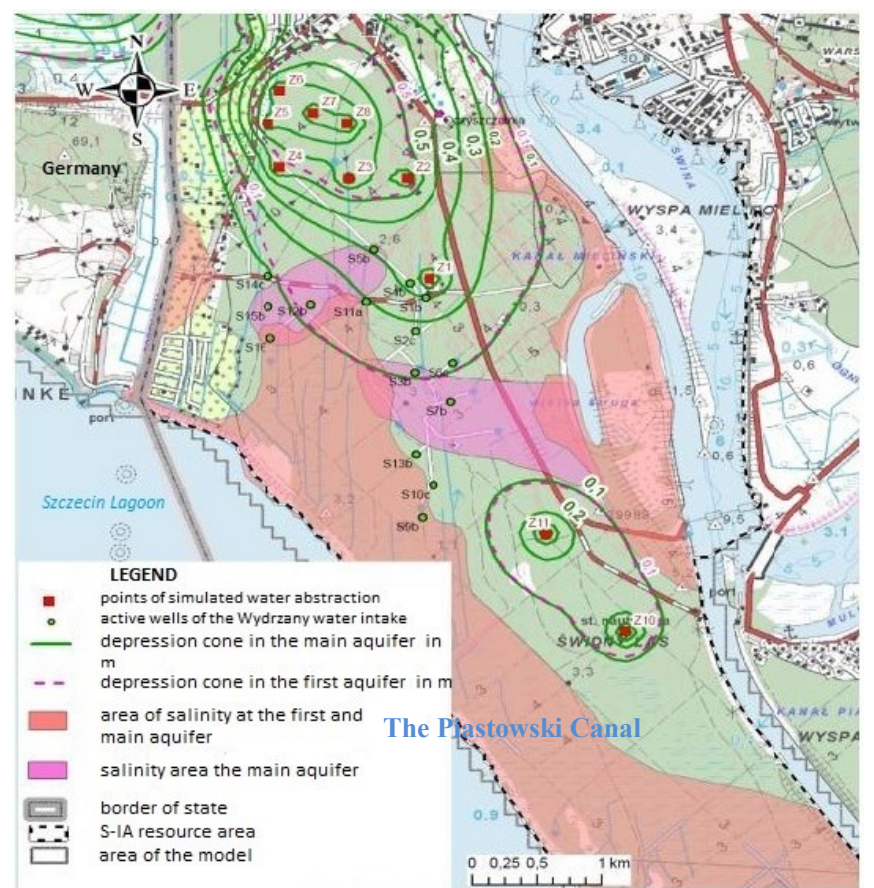

Figure 4. The range of the depression of the water intake after shifting the intake, on the background of documented saline groundwater.

\section{LITERATURE}

Matkowska Z., 1997 - Hydrogeological map of Poland in scale of 1:50 000, sheet Świnoujście with explanations [in Polish, English sum]. PGI-NRI. Warszawa.

Matkowska Z., Ruszała M., Wdowiak M., 1977 - Detailed geological map of Poland on a scale of 1: 50000 sheet Świnoujście i Międzyzdroje with explanations. [in Polish, English sum]. PGI-NRI. Warszawa.

Wiśniowski Z., Hoc R., Jezierski P., 2014 - Appendix 1 to the hydrogeological documentation setting the distribution resources of the groundwater of the Miecdzyodrza balance registration, the Szczecin region, the islands and the west part of the Wolin island. Unpublished. [in Polish, English sum]. PGI-NRI. arch. of Pomeranian Branch. Szczecin. 